\title{
Smart Automation Technique to Collect Dry and Wet Waste using IOT Module: to Achieve our 'SBM' Mission
}

\author{
C.Jenifa Latha, Ramanarayan Sankriti, M.Chandra sekhar
}

\begin{abstract}
The global waste production in now a days is increasing at a rapid rate, it is predicated that it will give rise to 28 billion tonnes per year by 2051, one-third of the whole global Asian continent is majorly contributed by India and china. The Main objective of the proposed method is to achieve clean India mission abbreviated as SBM. To make our urban and rural areas surrounding to be clean without any dry and wet waste. So our proposed method is designed to collect dry and wet Waste using IOT and embedded system Technology. The government has provided two dustbins in every place to dump the waste, one for dry waste and other for wet waste. The sensors node is kept inside the dustbins. When it becomes full it sends the signal to the Transmitter node. After Receiving the signal from sensor node, it updates details area and location in the common cloud IOT database. Then it sends the information to particular Location vehicle Driver to collect the waste.in the vehicle it has separate provision to collect dry and wet wate using conveyor belt and $h$ bridge motor driver circuit. After collecting the waste it updates the information to the common cloud database system. node
\end{abstract}

\section{INTRODUCTION}

In our country India producing nearly 58 million tonnes of waste per year. The per capita of waste generated in our country India ranges from $0.199 \mathrm{Kg}$ to $0.599 \mathrm{Kg}$. It is predicated that, especially in developed citys, produces 0.7 $\mathrm{kg}$ of waste per person per day. The advance development and growth in industry automations have created a major impact on the environment by affecting land, water, air, and noise pollution Due to this it reduces our purity in natural air, good water becomes polluted water. these things will lead to global warming, greenhouse gas, acid rain, etc. Dumping of huge plastic waste will affect the drought, as it gives chances to reduce our natural rainfall. The $75 \%$ of total waste will spoils our natural surrounding environment. ,by observing all the natural calamities it gives suggestions to dispose the waste materials properly without affecting the environment .This improper disposal of waste causes infectious and chronic diseases to humans and animals. The various charts show in the figure shows the total percentage of waste produced in every country

Revised Manuscript Received on September 10, 2019.

Dr C.Jenifa Latha, Professor \& Head, Department of Civil Engineering, Sethu Institute of Technology, Virudhunagar,Tamilnadu , India

(E-mail: jenifalatha@gmail.com)

Ramanarayan Sankriti, Research Scholar NIT,Trichy \& Assistant Professor/Dept. of Civil, Chaitanya Bharathi institute of Technology, Hyderabad, Telangana, India.

(E-mail: ramanarayan.s@gmail.com)

M.Chandra sekhar, Assistant Professor, Dept. of ECE, Pallavi Engineering college, Ranga reddy district, Hyderabad, Telangana, India.

(E-mail: patelnirzari84@gmail.com)
Chart 1: Percentage of World Food Wastage

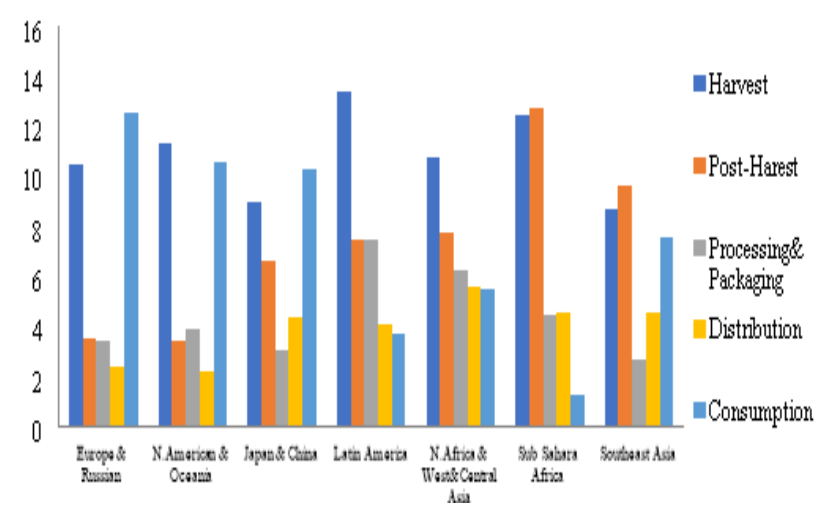

Chart 2: Electronic Waste by Top 10 Countries*

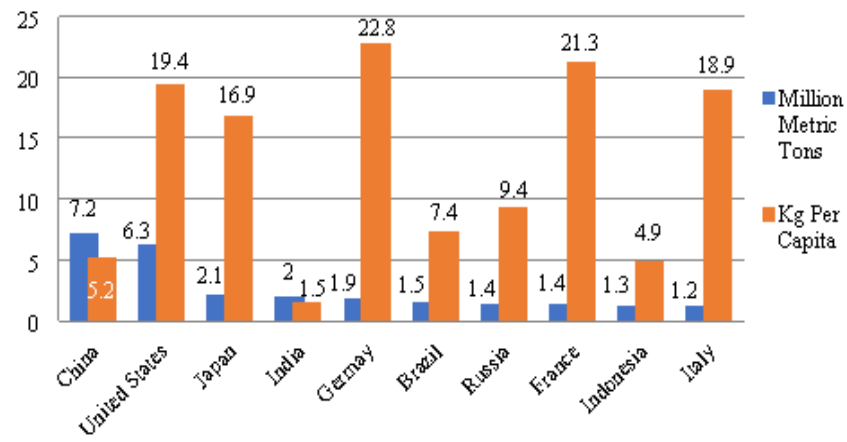

Chart 3: Percentage of Electronic Waste, Incinerated and Recycled

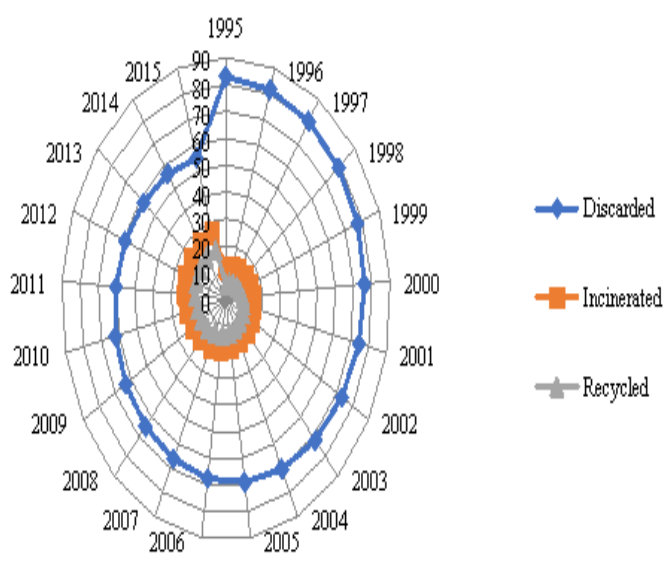

Published By:

Blue Eyes Intelligence Engineering 


\section{PROPOSED METHOD}

Generally, in Electronics Arduino is a open-source platform based on different embedded micro-controllers such as AVR, ARM, Atmega-8 etc. and it made ease of use in hardware interfacing device modules such as sensors, GPS, ZigBee, Motor direction control, Rf modules module, USB module. Bluetooth, WIFI etc. Arduino microcontrollers are instructed and coded using the Arduino Integrated Development Environment. It works and supports efficiently in Windows, Mac OS X, and Linux operating system.

In our proposed method Arduino UNO Embedded Microcontroller is employed in three modules. sensor node is placed on the dustbin to sense dry and wet waste, when it becomes full it sends the signal to the Transmitter node. The second module is transmitter node After Receiving the signal from sensor node it updates details such as area and location in the common cloud IOT database. The third module is Vehicle module it is placed inside vehicle. The transmitter node sends the information to particular Location vehicle Driver to collect the waste.in the vehicle it has separate provision to collect dry and wet waste using conveyor belt and h-bridge motor driver circuit controlled by vehicle node. After collecting the waste, it updates the information to the common think speak cloud database system

\section{Sensor Module:}

The sensor node module consist of obstacle sensor and RF module. It is placed inside the dustbin when it becomes full it enables the RF module to transmit the signal to the Transmitter node.

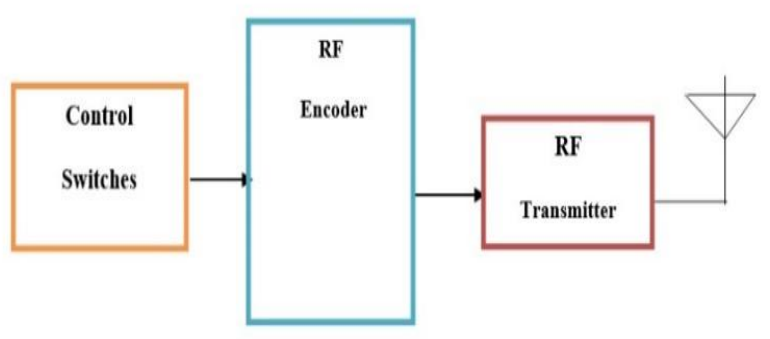

\section{Block diagram of Sensor module}

Vehicle Module:

In vehicle module We placed a conveyor belt on the dry and wet dustbins located in the common place. The Arduino Atmega 328 Microcontroller receives the input through the dust collecting labors to press the switch. By using the switch it sends the input signal to the at mega -8 Arduino embedded microcontroller then it sends the command to $\mathrm{H}$ Bridge to rotate the conveyor belt to dump the waste inside the vehicle. After that the empty dustbins are placed in the common place. After completing the process it updates the information in the common think speak cloud database.

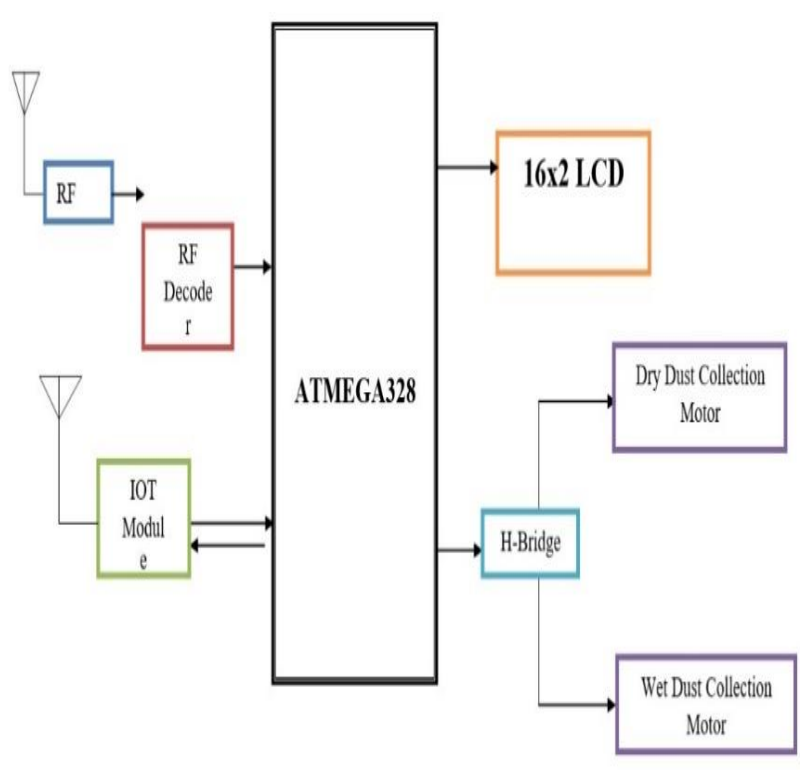

Block diagram of Vehicle Module

\section{HARDWARE DESCRIPTION \& RESULTS}

1.Features of Atmel ATmega328

- ATmega328 microcontroller operating at $5 \mathrm{~V} .2 \mathrm{~Kb}$ of RAM, $32 \mathrm{~Kb}$ of flash memory .

- $1 \mathrm{~Kb}$ of EEPROM for storing parameters.

- The clock speed is $16 \mathrm{MHz}$.

- The board has 14 digital I/O pins

- 6 analog input pins

\begin{tabular}{|c|c|}
\hline Microcontroller & ATmeza168/328 \\
\hline Operating Vottage & $5 \mathrm{~V}$ \\
\hline Input Vottage(recommended) & $7-12 \mathrm{~V}$ \\
\hline Input Vottage(Iimits) & $6-20 \mathrm{~V}$ \\
\hline Digital IOPins & 14 (of which 6 provide PMMoutput) \\
\hline Analog Input Pins & 6 \\
\hline DCCurrentper I/OPin & $40 \mathrm{~mA}$ \\
\hline DCCurrentior 3.3VPin & $50 \mathrm{~mA}$ \\
\hline Fash Memory & $\begin{array}{l}16 \text { KB (ATmezal } 68 \text { ) or } 32 \text { KB (ATmega328) of which } 2 \text { KB } \\
\text { usedby bootoader }\end{array}$ \\
\hline SRAM & 1 KB(ATmega168) or 2 KB(ATmega328) \\
\hline EPROM & 512 bytes (ATmega168) or 1 KB (ATmega328) \\
\hline Cock Soeed & $16 \mathrm{MHz}$ \\
\hline
\end{tabular}

Fig shows the features of Atmega 328 Embedded microcontroller 


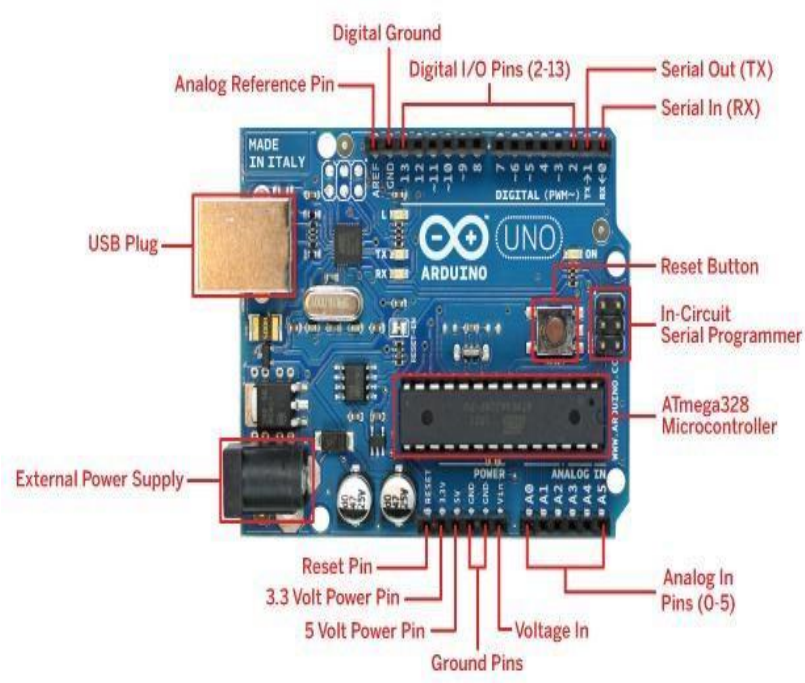

Fig Arudino Micro controller Hardware architecture

2. LCD Display :-

$>\quad$ It Display messages

$>16 \times 2$,Consist 16 columns and 2 rows

$>\quad$ Letters of alphabet, special characters, punctuation marks, mathematical symbols etc.

$>\quad$ Displays has built in backlight blue or green LED.

$>\quad$ When used during operation, a resistor for limiting the current should be used with any LED.

$>\quad$ The data is the ASCII value of the character to be displayed on the LCD.

$>\quad$ Disadvantage-contents will be lost upon the power off.

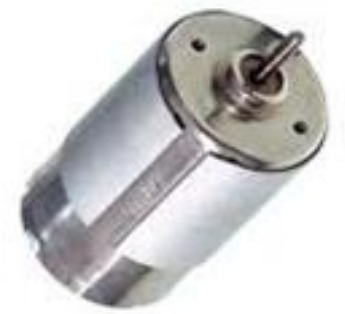

Fig a DC -Gear motor

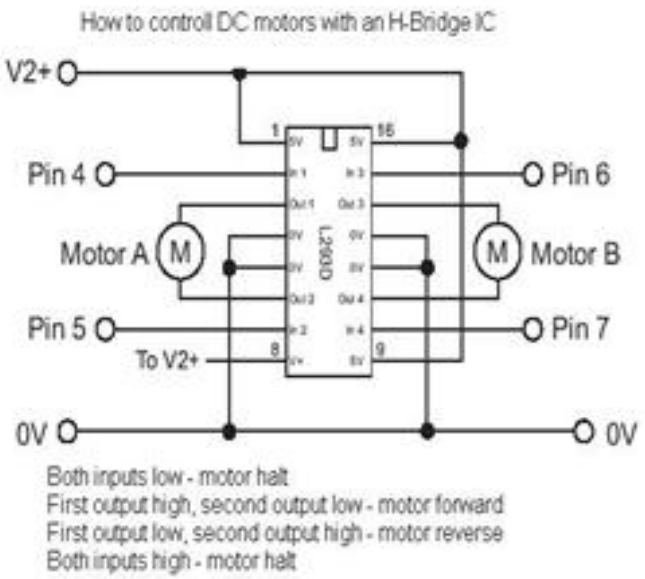

Fig c H-bridge L2830 motor driver IC
It has three control lines such as Enable,read/write and register select

Enable $(\mathbf{E}) \rightarrow$ Allows access to the display through R/W and RS lines. Low-LCD is disabled \& ignores signals from R/W \& RS.High-LCD checks the state of the 2 control lines $\&$ responds.

2.Read/Write $(\mathrm{R} / \mathrm{W})$ it Determines the direction of data between the LCD and microcontroller. Low-data is written to the LCD.High-data is read from the LCD.

Register select (RS) it interprets the type of data on data lines.

$\rightarrow$ Low- an instruction is being written to the LCD.

$\rightarrow$ High-a character is being written to the LCD.

3. DC-Motor \& H-bridge Driver IC :-

In this vehicle module we preferred DC motors having external gear arrangement attached with motor. These motors that are most commonly used in this module because they are have considerable torque to rotate the motor in clockwise and Anti-clock wise direction .we use a H-bridge motor driver circuit to lift and dump the waste inside the vehicle.

To control the DC motor motion operation of dry and wet waste separately . we use "Dual H-Bridge IC L293D" is employed in vehicle module.Only 4 possible switches can be used for DC motor rotation control, for clockwise rotation the position of switch S1-S4 ON, S2-S3 OFF, And for anti-clockwise rotation the position of switch S2-S3$\mathrm{ON}, \& \mathrm{~S} 1-\mathrm{S} 4 \mathrm{OFF}$

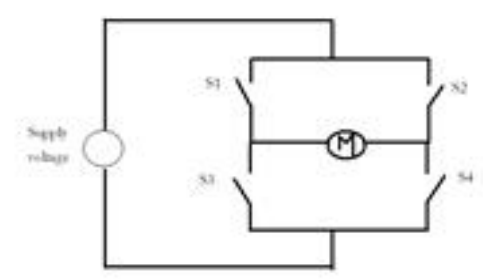

Fig B direction control using switches

\begin{tabular}{|c|c|c|c|c|}
\hline Direction & 4 & 5 & 6 & 7 \\
\hline Fonward & 1 & 0 & 1 & 0 \\
\hline Backward & 0 & 1 & 0 & 1 \\
\hline Left & 0 & 1 & 1 & 0 \\
Right & 1 & 0 & 0 & 1 \\
Soft Left & 0 & 0 & 1 & 0 \\
Soft Right & 1 & 0 & 0 & 0 \\
\hline Stop & 0 & 0 & 0 & 0 \\
\hline
\end{tabular}

Fig $D$ shows the rotation direction of dc motor 
When both the inputs are low as well as high means DC motor will stop rotating, if first pin (4)output is high and second pin(5) output is low the DC motor will rotate in forward direction (Clockwise ). Next condition if first pin (4) output is low and second pin output is high(5) the DC motor will rotate in reverse direction ( anti - Clockwise ). The table shows the direction control of DC motor based on the pin output. These pin configurations are coded inside the Arduino Microcontroller using Arduino IDE software.

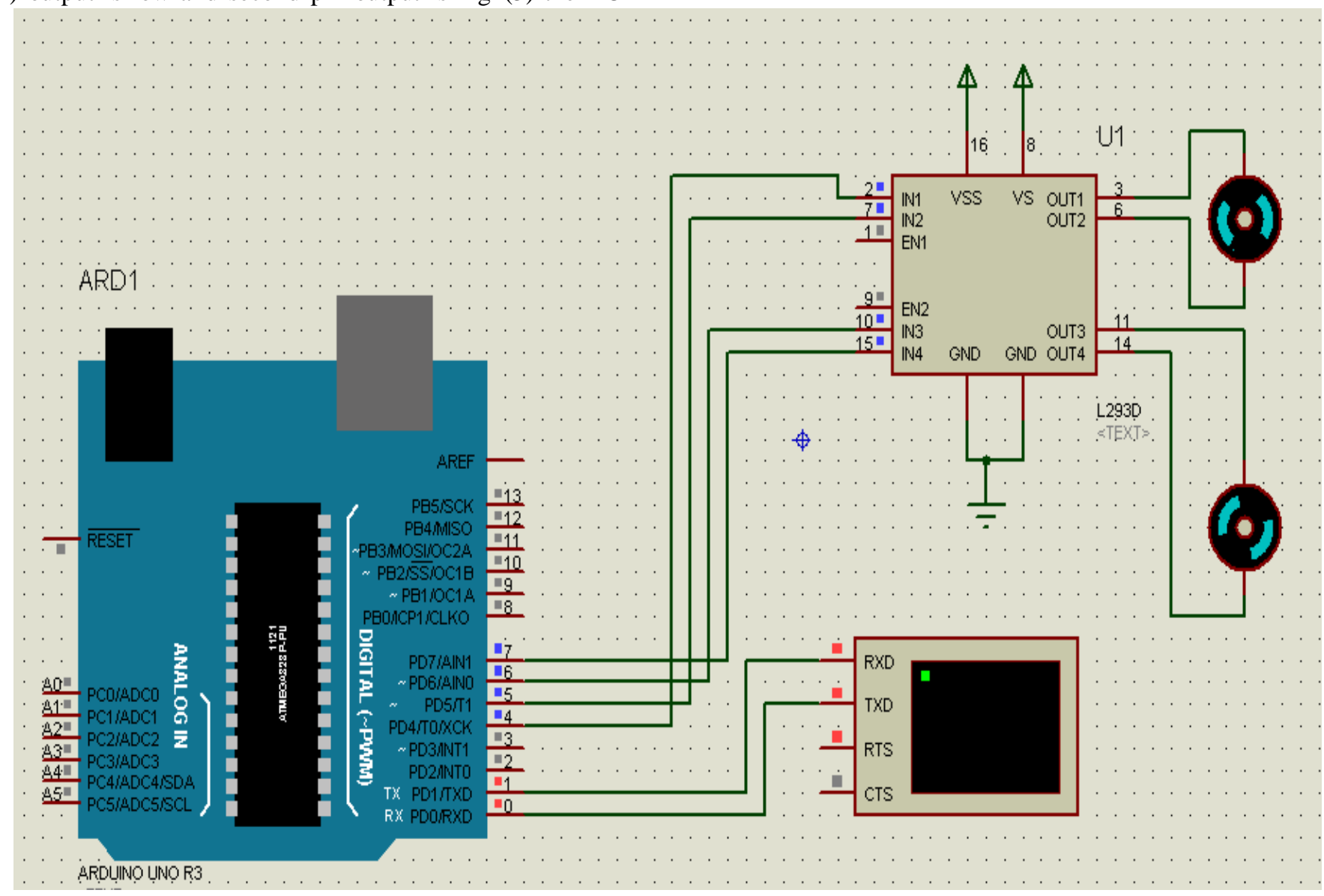

Fig shows the interfacing DC motor and H- bridge to Atmega 328 microcontroller

\section{Think speak Cloud Database :-}

The sensor node module is placed inside the dry and wet dustbins, it consist of a RF module transmitter, receiver, sensors and microcontroller when it becomes full it identifies using the object sensor and it transmits the signal to the Transmitter node. The second module is transmitter node After Receiving the signal from sensor node it updates details such as area and location in the common think speak cloud IOT database.

Graphs analysis:

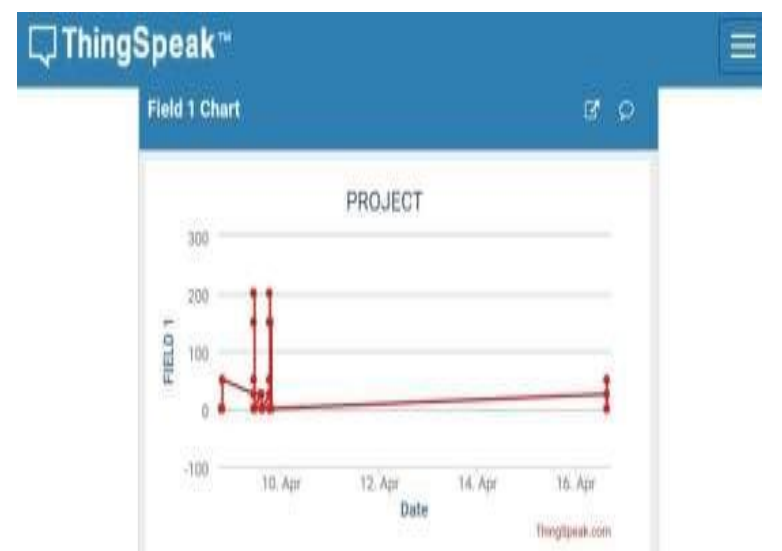

Figure: Vehicle Forward And Backward Movements

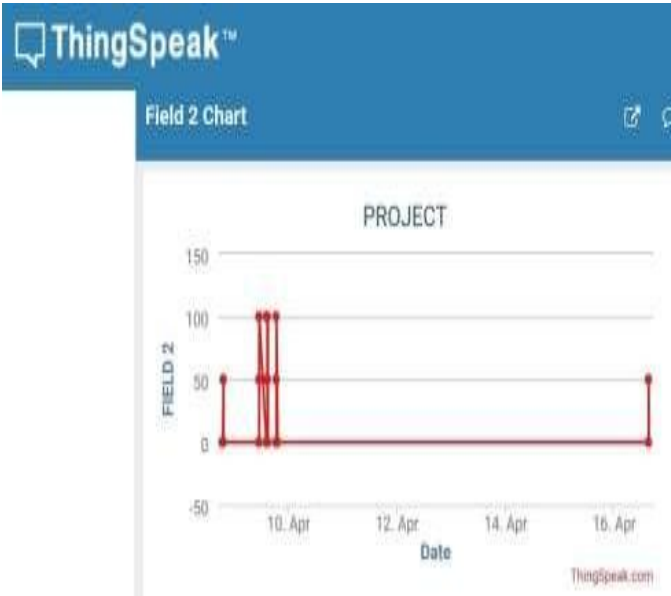

Figure: Dry Collection Monitoring 


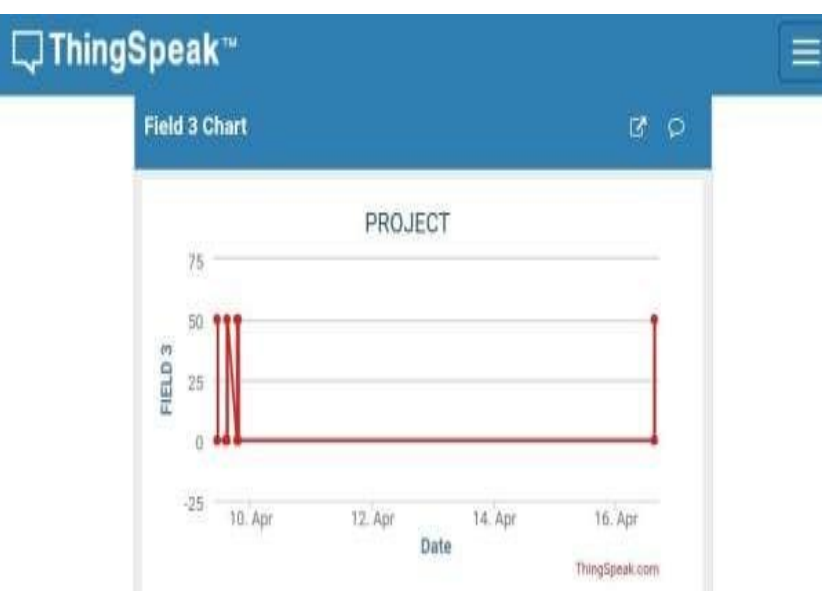

Figure: Wet Collection Monitoring

The third module is Vehicle module it is placed inside the vehicle. The transmitter node sends the information to particular Location vehicle Driver through the Android APP by commanding him to collect the waste in exact location. In that vehicle it has separate provision to collect dry and wet waste using conveyor belt and $\mathrm{H}$-bridge motor driver circuit controlled by vehicle node. After collecting the waste, it updates and monitors the data in common think speak cloud database system. The graph analysis shows the frequent updating of waste data in the think speak cloud database.

\section{CONCLUSION}

The proposed smart automation Technique to collect dry and wet waste using IOT module has practically working in efficient manner. whenever the waste is full in the dustbin situated in a common location in every area, it automatically passes the information to the transmitter module to collect waste from the particular location. The transmitter module will update the exact location and place of the waste in the think speak cloud database. And then the transmitter node passes the information to exact location vehicle driver through an android APP by commanding him to collect the waste. The vehicle has a provision to collect and dump separate dry and wet waste using conveyor belt and h-bridge motor driver circuit controlled by vehicle node. After collecting the waste in each and every area, it updates the information in think speak cloud Database. Using the think speak cloud database it can continuously monitor every location updates the details about waste collection. In day to day life in our surrounding environment the waste collection will increases or decreases it makes the think speak cloud system database to be updated frequently. The proposed method finally created a path to achieve our government 'SBM' Swach Bharat Mission to keep our surrounding to be clean .

\section{REFERENCES}

1 S.Sakai, S.E.Sawell, A.J.Chandler, "World Trends in Municipal Solid Waste Management "e, Environmental Preservation Centre, Vol 16, page 341, 1996,Kyoto University, Japan.

2 Yamazaki, H. NakaneG and A. Tanaka, "Basic Analysis of a Metal Detector," IEEE Instr. and Meas., vol.51, no. 4, pp. 810-814, August 2002.
3 Carullo.A, ParvisM, “An Ultrasonic Sensor for Distance Measurement in Automotive applications, in: IEEE sensors journal,vol1 n 2,page no 143.

4 International Journal of Industrial Electronics and Electrical Engineering, ISSN: 2347- 6982 Volume-3, Issue-5, May-2015.

5 GeE 2008 : Indo Italian conference Green and Environment March 20-21, MAEER's MIT College of Engineering, Pune.

6 Municipal Solid Waste Management in Emerging Mega Cities: A case study of Pune City Indo Italian conference, 2012.

7 Bharadwaj B, M Kumudha, Gowri Chandra N, Chaithra G,"Automation Of Smart Waste Management Using IOT To Support Swachh Bharat Abhiyan" -A Practical Approach, Vol 5,Issue 10, October 2017 IEEE.

8 Parkash, Prabu V," IOT Based Waste Management for Smart City", 15680/IJIRCCE. 2016.

9 Palaghat Yaswanth Sai, "IOT Smart Garbage Monitoring System in Cities-An Effective Way to Promote Smart City", 2016, IJARCSSE

10 Abhimanyu Singh, Pankhuri Aggarwal, Rahul Arora, “ IOT based Waste Collection System using Infrared Sensors", 2016 IEEE.

\section{AUTHORS PROFILE}

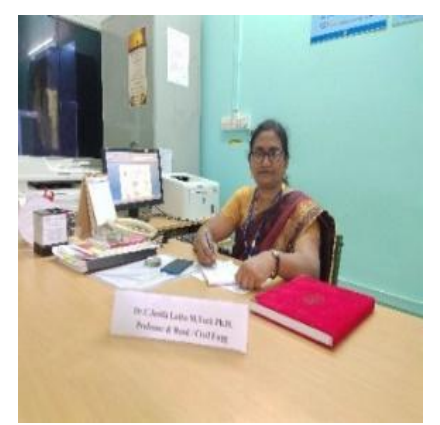

FIRST AUTHOR Dr. C. JenifaLatha received B.E degree in Civil Engineering from Government College of Engineering, Tirunelvelli, Tamil Nadu, M.Tech. in Water Resources Engineering from NIT, Trichy and Ph.D. from NIT, Trichy, Tamil Nadu. Published 7 journal publications and 14 conference publications. Co-Chair, in organizing the $2^{\text {nd }}$ International Conference on Recent Innovations in Engineering \& Technology in ASTRA, Hyderabad.Having 51/2 years of industrial experience, $4 \frac{1}{2}$ years of full time research experience and $171 / 4$ years of teaching experience, out of which 51/2years as Professor and Head of the Department. Currently working as Professor and Head in the Department of Civil Engineering, Sethu Institute of Technology (Autonomous), Virudhunagar, Tamil Nadu. Life Member of Indian Society of Technical Education (ISTE), Indian Association of Hydrologists, Indian Water Resources Society and Fellow member of Bose Science Society.Received, Sir M Visvesvaraya Best Scientist Award during 201718 , in recognition of dedication in Scientific Research \& Education from Bose Science Society, TN Scientific Research Organization, Best Entrant Award for the outstanding performance in Aurora's Scientific Technological \& Research Academy, for the academic year, 2016 - 2017, LEO Club Advisor Service Award in 2007 and Academic Proficiency Award for securing First Rank in I, II, III \& IV semesters of M. Tech in National Institute of Technology during 2002 - 2004.Interested in urban water resource research which includes Surface water hydrological processes and modeling, Rainwater harvesting and artificial groundwater recharge in semi-arid regions, Impact of Climate change on water resources, Non-conventional water resources (desalination, treated wastewater, recycled water) and waste management with environmental concern. This will address the water availability, water application technology, water-use efficiency and development of alternative water supplies for irrigated agriculture that ultimately consider its sustainability in the face of increasing climate change-environmental impacts and water shortages. This involves experimental work, field investigation, computer simulation and modeling as well as combination of these aspects. 


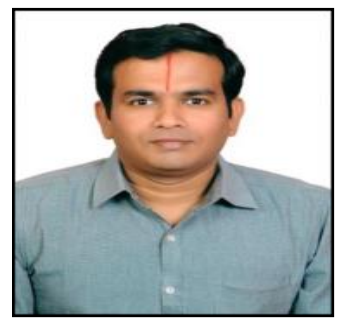

\section{Ramanarayan Sankriti}

Currently he is Pursuing Ph.D Programme in NIT,Tiruchirapalli. He received B.Tech degree in CIVIL from NIT Calicut and M.Tech degree in Remote Sensing \& GIS from JNTU Hyderabad. He Qualified GATE 2017 and GATE 2018 with All India Rank 8501 and 8518 respectively. He completed PG Diploma in Management from NICMAR-Pune, a SIRO (Scientific Industrial Research Organization) institute. He is an Associate member of Institution of Engineers, India and Member of Indian Society of Technical Education. He Has good student rating of above 4.0/5.0 in subjects like Remote-sensing and GIS. He Successfully completed the "Higher Surveying" ,"Natural Hazards Part I" and "MATLAB programming for Numerical Computation" (NPTEL Online Certification Courses). Currently he is working as an Assistant Professor in the Department of CIVIL. Chaitanya bharathi institute of Technology,Hyderabad.

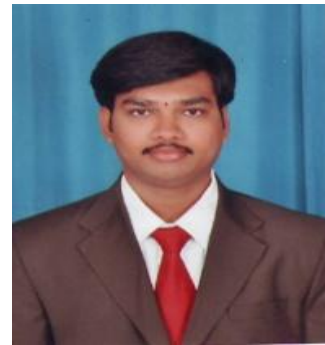

M.CHANDRA SEKHAR received B.Tech degree in ECE from JNTU Ananthapuram and M.Tech degree in Embedded Systems from JNTU Ananthapuram. Currently working as an Assistant Professor in the Department of ECE, Pallavi Engineering College, Hyderabad .Areas of interests are Digital electronics, embedded systems, Processors \& Controllers. 